\title{
Model identification of stomatognathic muscle system activity during mastication
}

\author{
EDWARD KIJAK ${ }^{1}$, JERZY MARGIELEWICZ ${ }^{2}$, DANUTA LIETZ-KIJAK ${ }^{3}$, \\ KATARZYNA WILEMSKA-KUCHARZEWSKA ${ }^{4}$, MAREK KUCHARZEWSKI $^{5}$ and ZBIGNIEW ŚLIWIŃSKI ${ }^{6}$

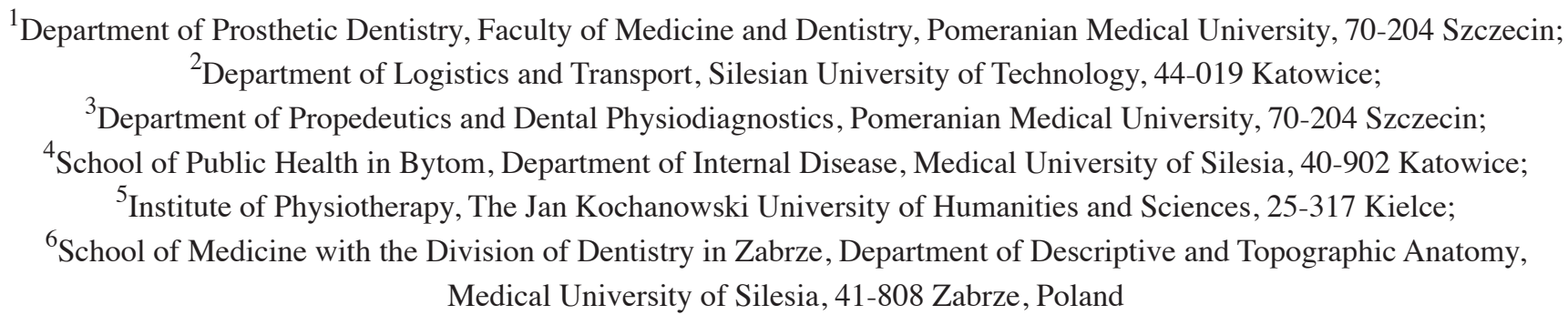

Received September 13, 2015; Accepted February 11, 2016

DOI: $10.3892 /$ etm.2016.3921

\begin{abstract}
The present study aimed to determine the numeric projection of the function of the mandible and muscle system during mastication. An experimental study was conducted on a healthy 47 year-old subject. On clinical examination no functional disorders were observed. To evaluate the activity of mastication during muscle functioning, bread cubes and hazelnuts were selected $\left(2 \mathrm{~cm}^{2}\right.$ and $1.2 / 1.3 \mathrm{~cm}$ in diameter, respectively) for condyloid processing. An assessment of the activity of mastication during muscle functioning was determined on the basis of numeric calculations conducted with a novel software programme, Kinematics $3 D$, designed specifically for this study. The efficacy of the model was verified by ensuring the experimentally recorded trajectories were concordant with those calculated numerically. Experimental measurements of the characteristic points of the mandible trajectory were recorded six times. Using the configuration coordinates that were calculated, the dominant componential harmonics of the amplitude-frequency spectrum were identified. The average value of the dominant frequency during mastication of the bread cubes was $\sim 1.16 \pm 0.06 \mathrm{~Hz}$, whereas in the case of the hazelnut, this value was nearly two-fold higher at $1.84 \pm 0.07 \mathrm{~Hz}$. The most asymmetrical action during mastication was demonstrated to be carried out by the lateral pterygoid muscles, provided that their functioning was not influenced by food consistency. The consistency of the food
\end{abstract}

Correspondence to: Dr Edward Kijak, Department of Prosthetic Dentistry, Faculty of Medicine and Dentistry, Pomeranian Medical University, Rybacka 1, 70-204 Szczecin, Poland

E-mail: edward.kijak@pum.edu.pl

Key words: biomechanics, stomatognathic system, modelling, muscle activity products had a decisive impact on the frequency of mastication and the number of cycles necessary to grind the food. Model tests on the function of the masticatory organ serve as effective tools since they provide qualitative and quantitative novel information on the functioning of the human masticatory organ.

\section{Introduction}

One of the basic functions carried out by the stomatognathic system is the collection and grinding of food. Mastication is considered to be the initial phase of food digestion (1-3). Mastication occurs as a result of the force-movement field, and is carried out via a complex interaction between muscle systems, teeth, lips, cheeks, the palate, salivary glands and the temporomandibular joints (4-7). Correct mastication should proceed on both sides of the dental arch openings, since one-sided mastication is the source of an uneven load of the temporomandibular joints (8-10). An important element of mastication which determines the appropriate mechanical grinding of food are the teeth, located in the maxilla and the mandible (11-14). From a mechanical point of view, the predominant tasks of the teeth are biting, grinding and crushing. Each type of tooth is adapted to different functions: The incisors are used for bitting and cutting, the canines for tearing food (15), and the premolars and molars for crushing and chewing food. In the initial phase of mastication, food introduced into the oral cavity is ground, mixed and moistened with saliva, which is supplied to the oral cavity via salivary glands. The duration of mastication proceeds until the moment when food, adequately ground and moistened with saliva, is formed into smaller bites and then swallowed. The ability to grind is an individually variable feature and has a crucial impact on the later phase of digestion, taking place in further sections of the alimentary tract (16). A significant influence on the efficacy of this physiological activity is the stomatognathic muscle system, which occurs as a result of the complex, peri- 
odical abduction and adduction movements of the mandible. Trajectories made by the incisors in a single mastication cycle resemble in their shape a deformed ellipse (17-19). Additionally, in each cycle it is possible to distinguish the abduction movement, the scope of which depends on the size of the bite and the consistency of the fragmented food (20-26). Lundeen and Gibbs (27) reported that if the fragmented food was characterized by hardness, then the scope of the lateral shifts of the mandible increase. In addition, the hardness of the bites has a decisive impact on the number of mastication cycles; the harder the food, the more cycles are required in order to obtain an adequate consistency for swallowing (28). In the initial phase of crushing, the alimentary bite decreases the distance between the antagonistic teeth. When this distance is $\sim 3 \mathrm{~mm}$, the cusps of the mandibular teeth are located nearly directly under the cusps of the maxillary teeth. This is the starting point for the second phase, consisting of trituration of the morsel of food. This stage depends strictly on the topography of the cusps and the geometry of the tooth slopes and furrows. Mandibular movement, responsible for grinding food, proceeds until the cusps of the mandibular teeth are in contact with the maxillary teeth furrows. Initial research suggested that antagonistic teeth do not come into contact during mastication (29), although in later investigations the presence of contact was demonstrated $(30,31)$. The frequency of contact between the teeth increases with the gradual grinding of a food morsel, and contact occurs in the final mastication cycles immediately prior to swallowing (32).

For the purpose of the present study, an experiment was conducted which aimed to identify a numeric reflection of the movement of the mandible and of the stomatognathic muscle system during mastication.

\section{Materials and methods}

Subject. An electronic facebow (Zebris JMA20, Zebris Medical GmbH, Allgäu, Germany) was used to record spatial movements of the mandible during food mastication. Recording of the mandible movements, reflecting mastication, were carried out in a 47 year-old healthy person in whom, during clinical examination, no functional disorders in the mastication muscle system were observed. The study was conducted in the Laboratory Diagnosis and Treatment of Dysfunction, the Department of Prosthodontics of the Pomeranian Medical University. The patients involved were all volunteers. Men with similar parameters (height and weight) aged between 34 to 47 years old (average 39.83 years old) with full dentition and without any dysfunction within the masticatory system were selected. Only one 47 year-old healthy person, during clinical examination, was observed to lack a single tooth mandibular tooth no. 36. Routine clinical testing demonstrated the presence of composite filling in all molars and insignificant abrasion of the cusps and incising edges of the other teeth. The degree of loss of dental hard tissues were determined to be $\mathrm{I}^{\mathrm{o}}$ and $\mathrm{II}^{\circ}$ according to the Martin scale (33). Contact between the antagonistic teeth occurred in the correct triads with the occlusion type protected by the canines. In addition, no occlusion obstructions were observed, such as premature contact during dynamic occlusion. The subject did not report any disorders of the teeth or any other elements of the stomatognathic system.
The only reported disorder was periodical teeth occluding, which occurred as a method for relieving stress in moments of emotional excitement. The present study was approved by the Ethics committee of the Pomeranian Medical University, Szczecin (no. KB-0012/30/13). All patients gave written informed consent to testing.

The mandibular kinematics. The formal basis of carrying out model researches on mandible kinematic movements were incisor and candylar process trajectory Trajectories on the condyloid process and incisor heads were recorded with an electronic Zebris JMA facebow following the placement of a portion of food in the oral cavity. Completion of the measurements was determined by the moment, in which total fragmentation finalized by swallowing occurred. Clinical tests were carried out 6 times per portion of bread $\left(2 \mathrm{~cm}^{2}\right.$ cube) and hazelnuts $(1.2 / 1.3 \mathrm{~cm}$ in diameter). Based on the trajectories of the condyloid processes and incisors, the configuration coordinates of the spatial model for the mandibular kinematics were calculated on the basis of which length and spatial orientation the mastication muscles were located. The first stage of the model research is to calculate the configuration coordinates of the numerical model of the lower jaw (Fig. 1A). These calculations are carried out on the basis of data recorded by an electronic facebow Zebris JMA. Formulated verification criteria, confirming compliance trajectory of the incisors (pts. C Fig. 1A) and the heads of the condylar process (pts. AiB, Fig. 1A), calculated numerically and registered in a clinical trial confirms the correctness of the mandible numerical model. A model verified in this way is still used for the numerical calculation of the average change in stomatognathic system muscles length. A numerically calculation of the average change in length of masticatory muscles can be experimentally verified only by taking measurements on pictures taken using X-ray imaging techniques: magnetic resonance imaging or computer tomography. Such verification can be useful for planning the therapy for patients with disabilities, for instance after condylar jaw fracture.

Mathematical and Engineering techniques such as automation and robotics were used. As a result configuration coordinates of the mathematical jaw model were calculated (Equation 1). In addition, the spatial configuration of the jaw was calculated (Equation 2) and it was used as a reference for the identification of accidental points of the jaw representing the movable muscle attachments in the stomatognathic system (Equation 3). The knowledge of the Cartesian coordinates imitating (at any point in time) the spatial position of the movable muscle attachments allowed us to determine the average change in length (Equation 4) and the spatial orientation of the muscle fibres (Equation 5). It should be emphasized that the authors of the present study did not come across any other similar approach to the kinematics of the lower jaw and the muscles during the review of the Literature.

In order to improve the numeric calculations, original Kinematics 3D software version 10.5.60 (WinJaw Evaluation software, Zebris Medical GmbH) was developed, in which mastication was mathematically reflected for the bread and hazelnuts. This program provides all the necessary information about the kinematics of the mandible and masticatory muscles registered in clinical trials, which can be verified by experimental research. For example, we can see how changing 
one factor, (eg. muscle length) affects other movement parameter characteristics for the patients lower jaw. The first stage of the examination was done on the basis of the registered incisors trajectory (point C, Fig. 1A) and the mandibular condyles (points A and B, Fig. 1A) that calculates the coordinates of the configuration of the jaw. On this basis it is possible to further assess the changes in length of the muscle fibers of the masseters (Fig. 1B).

In computer simulations for the mathematical description of the human body movement, kinematic chains with an open structure are most often used. Movement of the biomechanism reflecting the functioning of the mastication muscles may be modelled using the Cartesian or polar coordinates. In addition, as is the case with technical systems, the position and orientation of particular biosegments is described with respect to an immovable reference system. From a mechanical point of view, two kinematic tasks may be distinguished: A simple task, which is the identification of trajectories on which typical biomechanical points move based on present configuration coordinates, and the so-called reverse task, which consists in the identification of the configuration coordinates (Cartesian coordinates) that reflect the trajectories of characteristic biomechanical points. No matter which kinematic task is the object of the model tests, during their solution, it is necessary to have a kinematic model that is formulated accordingly. In the present study, spatial mandibular movement was projected using an open kinematic chain with a configuration of variable in time.

Identification of configuration coordinates. The $x_{\mathrm{O}}, y_{\mathrm{O}}, z_{\mathrm{O}}$ reference system in respect of which calculations are conducted may be assumed in any manner, and can be located for instance in the central part of the section connecting the condyloid process heads of the mandible (point D; Fig. 1A). However, such a location results in specific difficulties, including uncertainties during the calculations, such as the substitution averaging points that define the location of the muscles in the three dimensional space. For this reason and to eliminate these issues, it is necessary to introduce an additional $x_{\mathrm{P}}, y_{\mathrm{P}}, z_{\mathrm{P}}$ coordinate system. This mathematical procedure does not complicate the numeric calculations and may be interpreted as an expansion of the model by an additional segment, the orientation of which remains constant during the mandibular movements.

The numerical calculations were used with the application of the algorithm of Fourier fast transformation. Fourier spectral analysis is one of the most popular tools to judge the parameters and properties of the signal by spreading it on the harmonic amplitude frequency spectrum. Spectral analysis of signals is widely used as a result of the computer technology development. Getting faster and optimized algorithms in numerical methods allow you to perform any analysis of the spectral signal in a fast and precise way without the knowledge of the explicit representation of the analytical record. Direct calculation of the discrete Fourier transform (DFT)requires $\mathrm{N} 2$ multiplication and addition, where $\mathrm{N}$ defines the number of samples analyzed signal. In order to speed up the calculation, the so-called Fast Fourier Transform (FFT) is used with the Cooley and Tukey algorithms. Another approved procedure is a modification of the FFT algorithms, Cooley and Tukey, which uses the radix- 2 algorithm. For an even number of samples $\mathrm{N}$, it allows the breakdown of DFT on the two interleaved smaller size $\mathrm{N} / 2$, resulting in a number of necessary mathematical operations being halved compared to the classical DFT. Currently, the radix-2 algorithm is the most common numerical procedure whereby it is possible to reduce the necessary number of arithmetic operations $(\mathrm{N}-\ln (\mathrm{N}))$. The shorter computation time of harmonic components achieved is caused by the elimination of unnecessary intermediate records performed in the computer's memory.

In the model adopted for the numeric tests, three coordinates define the spatial orientation of the mandible $\left(\Phi_{3}, \Phi_{4}, \Phi_{5}\right)$, and the others reflect the lifting movement $\left(q, \Phi_{1}, \Phi_{2}\right)$. The first step in forming a mathematical model of the kinematics of the jaw is a solution to the simple equation. This stage is necessary since it provides information with regard to the structure of the equations, which is used to derive analytical associations describing the relationships between the configuration coordinates of the model and the recorded trajectories during clinical examination. The present study is limited only to specifying the final equations, describing the association between configuration and Cartesian coordinates (equation 1):

$$
\begin{gathered}
q=\sqrt{\left(x_{D}-x_{0}\right)^{2}+\left(y_{D}-y_{0}\right)^{2}+\left(z_{D}-z_{0}\right)^{2}}, \quad \varphi_{1}=\arctan \left(\frac{y_{D}-y_{0}}{x_{D}-x_{0}}\right), \quad \varphi_{3}=\arctan \left(\frac{y_{C}-y_{D}}{x_{C}-x_{D}}\right), \\
\varphi_{2}=\arctan \left(-\frac{\left(z_{D}-z_{0}\right)\left(\cos \varphi_{1}+\sin \varphi_{1}\right)}{\left(x_{D}-x_{0}\right)+\left(y_{D}-y_{0}\right)}\right), \quad \varphi_{4}=\arctan \left(-\frac{\left(z_{C}-z_{D}\right)\left(\cos \varphi_{3}+\sin \varphi_{3}\right)}{\left(x_{C}-x_{D}\right)+\left(y_{C}-y_{D}\right)}\right), \\
\varphi_{5}=\arctan \left(\frac{\left(\left(x_{A}-x_{D}\right)+\left(y_{A}-y_{D}\right)\right) \cos \varphi_{4}}{\left(z_{A}-z_{D}\right)\left(\sin \varphi_{3}-\cos \varphi_{3}\right)}-\frac{\sin \varphi_{4}\left(\cos \varphi_{3}+\sin \varphi_{3}\right)}{\left(\sin \varphi_{3}-\cos \varphi_{3}\right)}\right) .
\end{gathered}
$$

Identification of Cartesian coordinates. The factor that determines the mastication organ functioning is the muscular system controlled by the central nervous system. In order to determine the numeric projection of the motor activity of particular muscle fibres, appropriate mathematical associations must be defined. These associations are derived on the basis of the identified configuration coordinates (equation 1). In order to determine, using theoretical considerations, the scope of the changes in length and spatial orientation of specific groups of muscles, the Cartesian coordinates typical of attachment locations must be determined using the following formula, in which $\mathrm{P}_{\mathrm{i}}^{\mathrm{T}}$ is the vector defining the location of the muscle attachment ' $i$ ' associated with the mandible, for the selected orientation and location of the mandible; $\mathrm{P}_{\mathrm{i}}^{0}$ is the vector defining the location of the muscle attachment ' $i$ ' associated with the mandible at the resting position; $P_{D}$ is the vector defining the location of point D (Fig. 1); and R the orientation matrix of the mandible (equation 2):

$$
\mathbf{P}_{\mathrm{i}}^{\mathrm{T}}=\mathbf{P}_{\mathrm{D}}+\mathbf{R} \cdot \mathbf{P}_{\mathrm{i}}^{\mathbf{0}},
$$

The model assumes the resting position of the mandible, which is a characteristic of opening dental arches. A characteristic feature in the rest position is a jaw-jaw distance, or alternatively the lack of occlusal contact between opposing dental arches. A characteristic feature of the resting position is the downwards shift of the jaw, which results in the opening of occlusion surfaces of the dental arches. Following the measurement of the distance between the teeth in the resting position, the resting gap in normal occlusion conditions was previously determined to be $2-4 \mathrm{~mm}$ (34). In addition, in the resting position the muscle adductors and abductors are in balance, therefore, muscle function is only balancing the weight of the 
Table I. Extent of the shifts in the measurement points of the mandible presented as the mean \pm standard error.

A, Mastication of bread $(n=6)$.

\begin{tabular}{|c|c|c|c|c|c|c|c|c|c|}
\hline \multirow[b]{2}{*}{ Item } & \multicolumn{3}{|c|}{ Right condyloid process } & \multicolumn{3}{|c|}{ Left condyloid process } & \multicolumn{3}{|c|}{ Incisors } \\
\hline & $\mathrm{x}(\mathrm{mm})$ & $\mathrm{y}(\mathrm{mm})$ & $\mathrm{z}(\mathrm{mm})$ & $\mathrm{x}(\mathrm{mm})$ & $\mathrm{y}(\mathrm{mm})$ & $\mathrm{z}(\mathrm{mm})$ & $\mathrm{x}(\mathrm{mm})$ & $\mathrm{y}(\mathrm{mm})$ & $\mathrm{z}(\mathrm{mm})$ \\
\hline $\min$ & $-1.2 \pm 0.4$ & $-7.4 \pm 0.7$ & $-1.1 \pm 0.2$ & $-1.1 \pm 0.6$ & $-7.9 \pm 0.9$ & $-1.0 \pm 0.3$ & $-3.0 \pm 0.4$ & $-25.3 \pm 2.2$ & $-2.0 \pm 0.7$ \\
\hline $\max$ & $7.3 \pm 0.5$ & $1.2 \pm 0.5$ & $0.6 \pm 0.1$ & $13.2 \pm 1.3$ & $1.2 \pm 0.5$ & $1.0 \pm 0.2$ & $2.9 \pm 0.2$ & $2.4 \pm 1.2$ & $9.2 \pm 1.4$ \\
\hline
\end{tabular}

B, Mastication of hazelnuts $(n=6)$.

\begin{tabular}{|c|c|c|c|c|c|c|c|c|c|}
\hline \multirow[b]{2}{*}{ Item } & \multicolumn{3}{|c|}{ Right condyloid process } & \multicolumn{3}{|c|}{ Left condyloid process } & \multicolumn{3}{|c|}{ Incisors } \\
\hline & $\mathrm{x}(\mathrm{mm})$ & $\mathrm{y}(\mathrm{mm})$ & $\mathrm{z}(\mathrm{mm})$ & $\mathrm{x}(\mathrm{mm})$ & $\mathrm{y}(\mathrm{mm})$ & $\mathrm{z}(\mathrm{mm})$ & $\mathrm{x}(\mathrm{mm})$ & $\mathrm{y}(\mathrm{mm})$ & $\mathrm{z}(\mathrm{mm})$ \\
\hline $\min$ & $-1.9 \pm 0.4$ & $-7.4 \pm 1.0$ & $-1.3 \pm 0.4$ & $-1.2 \pm 0.3$ & $-9.4 \pm 0.6$ & $-1.2 \pm 0.4$ & $-3.9 \pm 0.9$ & $-21.9 \pm 1.1$ & $-1.7 \pm 1.0$ \\
\hline $\max$ & $5.7 \pm 0.4$ & $1.7 \pm 0.6$ & $1.6 \pm 0.1$ & $11.2 \pm 1.3$ & $1.4 \pm 0.5$ & $2.0 \pm 0.2$ & $2.1 \pm 0.4$ & $2.2 \pm 0.8$ & $9.6 \pm 0.7$ \\
\hline
\end{tabular}

Table II. Maximum extent of the changes in muscle fibre length during mastication.

\begin{tabular}{|c|c|c|c|c|c|c|c|c|}
\hline \multirow[b]{3}{*}{ Item } & \multicolumn{4}{|c|}{ Mastication of bread $(n=6)$} & \multicolumn{4}{|c|}{ Mastication of hazelnuts $(n=6)$} \\
\hline & \multicolumn{2}{|c|}{ On the right side } & \multicolumn{2}{|c|}{ On the left side } & \multicolumn{2}{|c|}{ On the right side } & \multicolumn{2}{|c|}{ On the left side } \\
\hline & $\Delta l_{\min }(\mathrm{mm})$ & $\Delta l_{\max }(\mathrm{mm})$ & $\Delta l_{\min }(\mathrm{mm})$ & $\Delta l_{\max }(\mathrm{mm})$ & $\Delta l_{\min }(\mathrm{mm})$ & $\Delta l_{\max }(\mathrm{mm})$ & $\Delta l_{\min }(\mathrm{mm})$ & $\Delta l_{\max }(\mathrm{mm})$ \\
\hline $\mathrm{M}_{\mathrm{SA}}$ & $-1.2 \pm 0.6$ & $20.0 \pm 1.1$ & $-1.1 \pm 0.6$ & $18.9 \pm 0.9$ & $-1.3 \pm 0.4$ & $15.8 \pm 0.7$ & $-1.4 \pm 0.5$ & $16.1 \pm 0.6$ \\
\hline $\mathrm{M}_{\mathrm{SP}}$ & $-1.0 \pm 0.5$ & $14.7 \pm 0.7$ & $-0.9 \pm 0.4$ & $13.5 \pm 0.6$ & $-1.2 \pm 0.3$ & $11.7 \pm 0.6$ & $-1.2 \pm 0.3$ & $11.9 \pm 0.4$ \\
\hline $\mathrm{M}_{\mathrm{DA}}$ & $-0.9 \pm 0.5$ & $14.2 \pm 0.7$ & $-0.9 \pm 0.4$ & $14.0 \pm 0.8$ & $-1.1 \pm 0.4$ & $11.5 \pm 0.5$ & $-0.9 \pm 0.2$ & $12.7 \pm 0.4$ \\
\hline $\mathrm{M}_{\mathrm{DP}}$ & $-0.9 \pm 0.4$ & $11.8 \pm 0.6$ & $-0.8 \pm 0.4$ & $11.3 \pm 0.6$ & $-1.2 \pm 0.4$ & $10.0 \pm 0.5$ & $-0.9 \pm 0.2$ & $10.9 \pm 0.3$ \\
\hline $\mathrm{P}_{\mathrm{A}}$ & $-1.0 \pm 0.5$ & $17.2 \pm 1.1$ & $-0.9 \pm 0.4$ & $15.9 \pm 0.6$ & $-1.1 \pm 0.3$ & $13.7 \pm 0.7$ & $-1.3 \pm 0.4$ & $12.8 \pm 0.6$ \\
\hline $\mathrm{P}_{\mathrm{P}}$ & $-0.9 \pm 0.4$ & $12.4 \pm 0.8$ & $-0.8 \pm 0.3$ & $11.6 \pm 0.4$ & $-0.9 \pm 0.2$ & $10.6 \pm 0.6$ & $-1.2 \pm 0.3$ & $9.9 \pm 0.5$ \\
\hline $\mathrm{L}_{\mathrm{U}}$ & $-2.7 \pm 0.3$ & $1.5 \pm 0.3$ & $-5.9 \pm 0.7$ & $0.8 \pm 0.3$ & $-3.9 \pm 0.3$ & $3.2 \pm 0.5$ & $-5.5 \pm 0.9$ & $1.2 \pm 0.5$ \\
\hline $\mathrm{L}_{\mathrm{P}}$ & $-3.4 \pm 0.3$ & $1.1 \pm 0.3$ & $-6.3 \pm 0.7$ & $0.7 \pm 0.3$ & $-4.4 \pm 0.3$ & $2.7 \pm 0.5$ & $-6.1 \pm 0.9$ & $0.8 \pm 0.4$ \\
\hline $\mathrm{L}_{\mathrm{L}}$ & $-7.2 \pm 0.4$ & $0.7 \pm 0.4$ & $-9.4 \pm 0.6$ & $0.8 \pm 0.5$ & $-7.9 \pm 0.3$ & $1.4 \pm 0.3$ & $-9.4 \pm 0.6$ & $0.5 \pm 0.1$ \\
\hline $\mathrm{T}_{\mathrm{V}}$ & $-1.4 \pm 0.7$ & $22.4 \pm 1.2$ & $-1.4 \pm 0.7$ & $22.9 \pm 1.3$ & $-1.2 \pm 0.5$ & $18.7 \pm 0.7$ & $-1.3 \pm 0.4$ & $21.0 \pm 0.6$ \\
\hline $\mathrm{T}_{\mathrm{A}}$ & $-1.3 \pm 0.7$ & $22.0 \pm 1.1$ & $-1.4 \pm 0.8$ & $24.1 \pm 1.6$ & $-1.1 \pm 0.6$ & $19.4 \pm 0.6$ & $-0.9 \pm 0.3$ & $23.2 \pm 0.7$ \\
\hline $\mathrm{T}_{\mathrm{P}}$ & $-1.1 \pm 0.6$ & $16.9 \pm 0.8$ & $-1.2 \pm 0.8$ & $19.7 \pm 9.2$ & $-1.1 \pm 0.5$ & $15.9 \pm 0.5$ & $-0.6 \pm 0.2$ & $19.9 \pm 0.6$ \\
\hline $\mathrm{D}$ & $-9.1 \pm 0.7$ & $1.9 \pm 0.6$ & $-8.4 \pm 0.6$ & $2.8 \pm 0.88$ & $-8.8 \pm 0.7$ & $2.0 \pm 1.14$ & $-7.4 \pm 0.8$ & $2.4 \pm 0.9$ \\
\hline
\end{tabular}

$M_{S A}$, superficial front fibres of the masticators; $M_{S P}$, superficial back fibres of the masticators; $M_{D A}$, deep front fibres of the masticators; $M_{D P}$, deep back fibres of the masticators; $P_{A}$, front fibres of the pterygoid-medial muscle; $P_{P}$, back fibres of the pterygoid-medial muscle; $\mathrm{L}_{\mathrm{U}}$, upper pad of the pterygoid-lateral muscle; $\mathrm{L}_{\mathrm{P}}$, transitional pad of the pterygoid-lateral muscle; $\mathrm{L}_{\mathrm{L}}$, lower pad of the pterygoid-lateral muscle; $T_{V}$, vertical fibres of the temporal muscle; $T_{A}$, transitional fibres of the temporal muscle; $T_{P}$, back fibres of the temporal muscle; $D$, group of suprahyoid muscles.

lower jaw and bioelectric muscle activity is minimal (35-40). A shifting mandible changes its orientation and position, and specific muscle groups become longer or shorter. The length and spatial orientation of the muscle fibres can only be approximately determined. This approximation is caused by the large surface space of the muscle attachments to the mandibular and cranial bones. Lack of precise criteria that would ensure the clear projection of the location of the muscle attachments results in the majority of model tests offering approximate solutions. Their advantage is the possibility of reducing the attachment surfaces to a single point. Therefore, this approach causes the lengths of specific groups of muscle fibres to be averaged.

General analytic association. The movement of muscles in the stomatognathic system was calculated in relation to a fixed coordinate system (point O, Fig. 1B). The local coordinate 
Table III. Ratios $\left(w_{\mathrm{P}}\right)$ of muscle mastication function presented as the mean \pm standard error.

\begin{tabular}{|c|c|c|c|c|c|c|c|c|}
\hline \multirow[b]{2}{*}{ Item } & \multicolumn{4}{|c|}{ Mastication of bread $(n=6)$} & \multicolumn{4}{|c|}{ Mastication of hazelnut $(n=6)$} \\
\hline & $\begin{array}{c}\Delta l \\
(m m)\end{array}$ & $\begin{array}{l}d \Delta l / d t \\
(\mathrm{~mm} / \mathrm{s})\end{array}$ & $\begin{array}{c}d^{2} \Delta l / d t^{2} \\
\left(\mathrm{~mm} / \mathrm{s}^{2}\right)\end{array}$ & Mean & $\begin{array}{c}\Delta l \\
(m m)\end{array}$ & $\begin{array}{l}d \Delta l / d t \\
(\mathrm{~mm} / \mathrm{s})\end{array}$ & $\begin{array}{c}d^{2} \Delta l / d t^{2} \\
\left(\mathrm{~mm} / \mathrm{s}^{2}\right)\end{array}$ & Mean \\
\hline $\mathrm{M}_{\mathrm{SA}}$ & $0.87 \pm 0.07$ & $0.81 \pm 0.09$ & $0.55 \pm 0.31$ & $0.74 \pm 0.10$ & $0.97 \pm 0.01$ & $0.96 \pm 0.01$ & $0.89 \pm 0.03$ & $0.94 \pm 0.02$ \\
\hline $\mathrm{M}_{\mathrm{SP}}$ & $0.70 \pm 0.16$ & $0.56 \pm 0.23$ & $0.25 \pm 0.32$ & $0.50 \pm 0.13$ & $0.94 \pm 0.01$ & $0.91 \pm 0.02$ & $0.78 \pm 0.06$ & $0.88 \pm 0.05$ \\
\hline $\mathrm{M}_{\mathrm{DA}}$ & $0.94 \pm 0.01$ & $0.84 \pm 0.06$ & $0.48 \pm 0.29$ & $0.75 \pm 0.14$ & $0.83 \pm 0.05$ & $0.91 \pm 0.01$ & $0.80 \pm 0.02$ & $0.84 \pm 0.03$ \\
\hline $\mathrm{M}_{\mathrm{DP}}$ & $0.92 \pm 0.02$ & $0.81 \pm 0.07$ & $0.45 \pm 0.28$ & $0.73 \pm 0.14$ & $0.85 \pm 0.05$ & $0.92 \pm 0.01$ & $0.80 \pm 0.03$ & $0.86 \pm 0.03$ \\
\hline $\mathrm{P}_{\mathrm{A}}$ & $0.74 \pm 0.13$ & $0.72 \pm 0.14$ & $0.58 \pm 0.22$ & $0.68 \pm 0.05$ & $0.58 \pm 0.12$ & $0.76 \pm 0.06$ & $0.73 \pm 0.05$ & $0.69 \pm 0.06$ \\
\hline $\mathrm{P}_{\mathrm{P}}$ & $0.71 \pm 0.16$ & $0.69 \pm 0.16$ & $0.48 \pm 0.31$ & $0.63 \pm 0.07$ & $0.53 \pm 0.12$ & $0.73 \pm 0.07$ & $0.68 \pm 0.06$ & $0.65 \pm 0.06$ \\
\hline $\mathrm{L}_{\mathrm{U}}$ & $0.00 \pm 0.00$ & $0.04 \pm 0.09$ & $0.00 \pm 0.00$ & $0.01 \pm 0.01$ & $0.00 \pm 0.00$ & $0.03 \pm 0.03$ & $0.01 \pm 0.01$ & $0.01 \pm 0.01$ \\
\hline $\mathrm{L}_{\mathrm{P}}$ & $0.02 \pm 0.06$ & $0.08 \pm 0.14$ & $0.00 \pm 0.01$ & $0.04 \pm 0.02$ & $0.00 \pm 0.00$ & $0.05 \pm 0.05$ & $0.03 \pm 0.03$ & $0.03 \pm 0.02$ \\
\hline $\mathrm{L}_{\mathrm{L}}$ & $0.46 \pm 0.14$ & $0.56 \pm 0.06$ & $0.28 \pm 0.17$ & $0.44 \pm 0.08$ & $0.14 \pm 0.09$ & $0.47 \pm 0.04$ & $0.30 \pm 0.08$ & $0.30 \pm 0.10$ \\
\hline $\mathrm{T}_{\mathrm{V}}$ & $0.99 \pm 0.00$ & $0.98 \pm 0.01$ & $0.83 \pm 0.21$ & $0.93 \pm 0.05$ & $0.95 \pm 0.02$ & $0.98 \pm 0.00$ & $0.96 \pm 0.00$ & $0.96 \pm 0.01$ \\
\hline $\mathrm{T}_{\mathrm{A}}$ & $0.90 \pm 0.04$ & $0.89 \pm 0.02$ & $0.75 \pm 0.11$ & $0.85 \pm 0.05$ & $0.74 \pm 0.06$ & $0.88 \pm 0.01$ & $0.83 \pm 0.01$ & $0.82 \pm 0.04$ \\
\hline $\mathrm{T}_{\mathrm{P}}$ & $0.80 \pm 0.09$ & $0.82 \pm 0.04$ & $0.61 \pm 0.13$ & $0.74 \pm 0.06$ & $0.59 \pm 0.09$ & $0.81 \pm 0.02$ & $0.74 \pm 0.01$ & $0.71 \pm 0.06$ \\
\hline $\mathrm{D}$ & $0.64 \pm 0.20$ & $0.59 \pm 0.19$ & $0.72 \pm 0.11$ & $0.65 \pm 0.04$ & $0.29 \pm 0.19$ & $0.58 \pm 0.12$ & $0.76 \pm 0.05$ & $0.54 \pm 0.14$ \\
\hline
\end{tabular}

$M_{S A}$, superficial front fibres of the masticators; $M_{S P}$, superficial back fibres of the masticators; $M_{D A}$, deep front fibres of the masticators; $M_{D P}$, deep back fibres of the masticators; $P_{A}$, front fibres of the pterygoid-medial muscle; $P_{P}$, back fibres of the pterygoid-medial muscle; $\mathrm{L}_{\mathrm{U}}$, upper pad of the pterygoid-lateral muscle; $\mathrm{L}_{\mathrm{P}}$, transitional pad of the pterygoid-lateral muscle; $\mathrm{L}_{\mathrm{L}}$, lower pad of the pterygoid-lateral muscle; $\mathrm{T}_{\mathrm{V}}$, vertical fibres of the temporal muscle; $\mathrm{T}_{\mathrm{A}}$, transitional fibres of the temporal muscle; $\mathrm{T}_{\mathrm{P}}$, back fibres of the temporal muscle; $\mathrm{D}$, group of suprahyoid muscles.
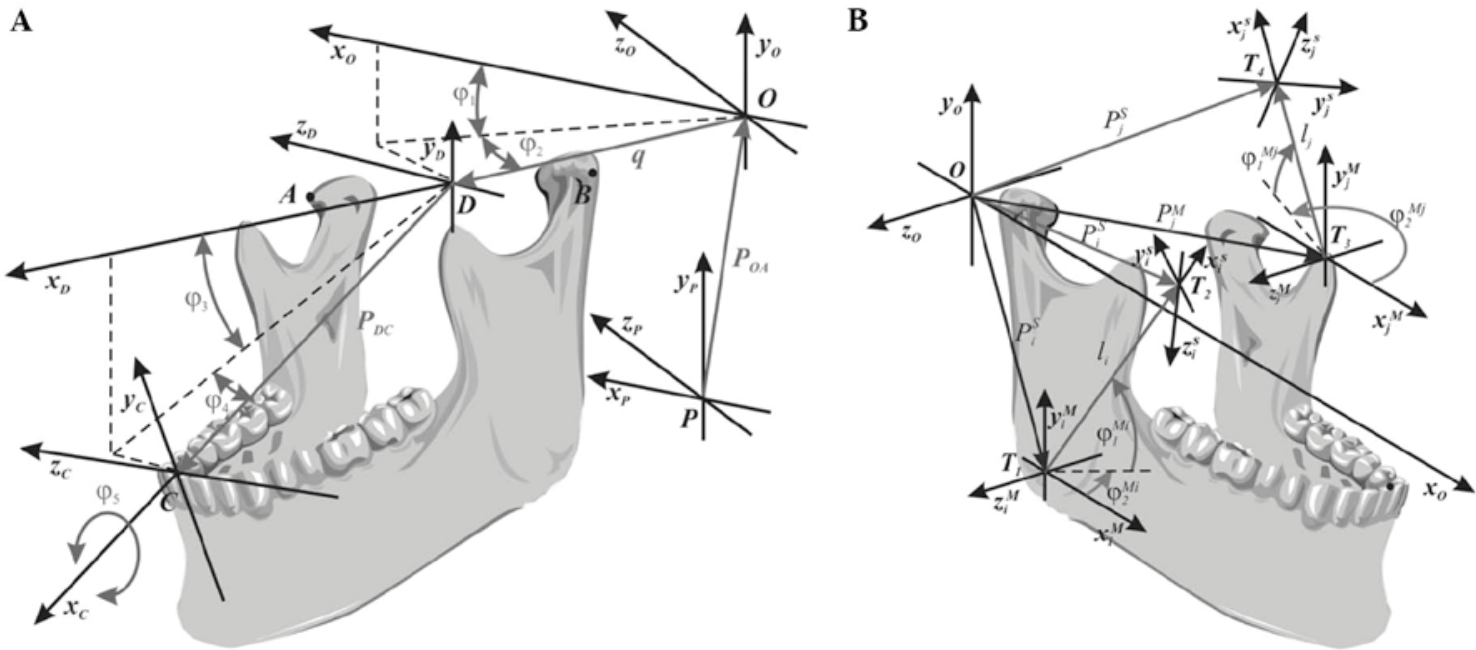

Figure 1. (A) Spatial orientation of the mandibular kinematics and (B) scheme used for the identification of the spatial orientation of the muscle fibres .

system $T_{2}$ represents the position of the muscle attachment ' $i$ ' to the skull, and this system is associated with the fixed reference system $\mathrm{O}$. On the other hand, the local variable coordinate system $T_{l}$ is associated with the attachment of the mandible muscle 'i'. In order to simplify the calculations, the same spatial orientation is specified for both the $T_{1}$ and $\mathrm{O}$ reference systems, given that this simplification has no effect on the identified averaged lengths or orientation of the muscle fibres. On the basis of the schematic diagram (Fig. 1B), a general analytical association was derived, which simultaneously considered the length of the mandibular muscle and its spatial orientation. In this formula,
$\mathrm{P}_{\mathrm{i}}^{\mathrm{S}}$ is the vector defining the position of the muscle attachment ' $\mathrm{i}$ ' associated with the skull; $\mathrm{P}_{\mathrm{i}}^{\mathrm{M}}$ the position of the muscle attachment ' $i$ ' associated with the mandible; $\mathrm{R}_{\mathrm{i}}^{\mathrm{Z}}$ and $\mathrm{R}_{\mathrm{i}}{ }^{\mathrm{Y}}$ the rotation matrixes relative to the axes $\mathrm{z}$ and $\mathrm{y}$; and $\mathrm{L}_{\mathrm{i}}=\left[\begin{array}{lll}l i & 0 & 0\end{array}\right]^{\mathrm{T}}$ is the vector defining the distance between local coordinate systems $\mathrm{T}_{1}$ and $\mathrm{T}_{2}$ (equation 3):

$$
\mathbf{P}_{\mathrm{i}}^{\mathrm{S}}=\mathbf{P}_{\mathrm{i}}^{\mathrm{M}}+\mathbf{R}_{\mathrm{i}}^{\mathrm{Z}} \cdot \mathbf{R}_{\mathrm{i}}^{\mathrm{Y}} \cdot \mathbf{L}_{\mathrm{i}},
$$

Calculation of the average muscle length. The average length of the muscle is calculated based on the average of Cartesian 
coordinates that define the position of muscle trailers to the mandible and the skull (equation 4):

$$
l_{i}=\sqrt{\left(x_{i}^{M}-x_{i}^{S}\right)^{2}+\left(y_{i}^{M}-y_{i}^{S}\right)^{2}+\left(z_{i}^{M}-z_{i}^{S}\right)^{2}} .
$$

In the above equation, the $x_{\mathrm{i}}, y_{\mathrm{i}}, z_{\mathrm{i}}$ coordinates represent the Cartesian coordinates of the muscle attachments, given that the superscripts marked with the symbol ' $S$ ' correspond to the fixed attachments to the cranial bones, whereas symbol ' $M$ ' corresponds to the variable incidental attachments to the mandible. The change in the length of the mandibular muscle, manifested by the shortening or elongation $\Delta l$, is calculated as a difference between the resting length of the muscle $l_{\mathrm{i}}{ }^{0}$ and its length at any given time of the mandibular movement $l_{\mathrm{i}}$. The resting length of the functioning mastication muscles is associated with the position of the mandible at rest. Note that positive $\Delta l$ difference values may be interpreted as extensions of the mandibular muscle, whereas negative values as shortening of the mandibular muscle. Angles $\varphi_{1}{ }^{M i}$ and $\varphi_{2}{ }^{M i}$ defining the spatial orientation of the muscle 'i' may be obtained by transformations of equation 3 (equation 5):

$$
\varphi_{1}^{M i}=\arctan \left(\frac{y_{i}^{C}-y_{i}^{Z}}{x_{i}^{C}-x_{i}^{Z}}\right), \varphi_{2}^{M i}=\arctan \left(\frac{-\left(z_{i}^{C}-z_{i}^{Z}\right) \cdot\left(\cos \left(\varphi_{1}^{M i}\right)+\sin \left(\varphi_{1}^{M i}\right)\right)}{\left(x_{i}^{C}-x_{i}^{Z}\right)+\left(y_{i}^{C}-y_{i}^{Z}\right)}\right) .
$$

Analytical associations based on data derived from equations 1-5 supplemented by data recorded during mandible movement on clinical examination are the formal basis for conducting numerical calculations on the activity of mastication muscle functioning.

\section{Results}

Trajectories of the incisors and Cartesian coordinates. The trajectories along which the incisors move in the front plane, reflecting the mastication of the bread and hazelnuts, are presented in Figs. 2 and 3. The first cycle was omitted, since the trajectories projected at this time are associated with the abduction movement, which has a negligent effect on the further course of mastication. The average minimum and maximum values of the shifts of the Cartesian coordinates, recorded using the electronic facebow, are shown in Table I.

Length of the muscle fibers. Bearing in mind the evaluation of the effect of particular groups of muscles on the process of occlusion, changes in their length in each cycle were calculated. The numeric values that were obtained were used to determine the extent of the changes in muscle fibre length. The average parameters, illustrating maximum shortening $\Delta l_{\min }$ or elongation $\Delta l_{\max }$ of the muscle fibres during mastication of the bread and hazelnuts, are shown in Table II.

The data presented in Table I do not clearly describe the degree of asymmetric function of the muscles located on either side of the mandible. For this reason, individual axes were assigned to changes in length $\Delta l$ of the muscles on the right and left side of the mandible (Fig. 4).

Coefficients of muscular work. Numerical data specified in this way, are referred to idealized situations (a straight line traversing the beginning of the coordinate system), which occurs when the muscles on both sides of the mandible function symmetrically. On this basis the identified muscle function coefficients $w_{\mathrm{P}}$ can be interpreted as a measure of their asymmetric or symmetric operation. With the assumption that muscle fibres are not elongated with constant speed $d \Delta l /$ $d t$ and permanent acceleration $d^{2} \Delta / d t^{2}$, the resultant operation was calculated as an arithmetic average from three kinematic sizes.

Length of the muscles in the act of chewing. Data presented in Table III should be interpreted as follows: If the ratio $w_{\mathrm{P}}$ has a value close to homogeneity, the muscle fibres function symmetrically; if however the ratio $w_{\mathrm{P}}$ is close to zero, the fibres function asymmetrically.

In the initial phase of mastication, the lateral pterygoid muscles are extended to their maximum lengths. Following increasingly broad dental arch opening, the lateral pterygoid muscles are supported by the suprahyoid muscles. Such a situation, in which the lateral pterygoid muscles have a dominant role, is a feature variable between individuals. The results of the computer simulations conducted as a part of this investigation indicate that the suprahyoid muscles initiate the abduction movement. Deviation of the trajectories of the incisors from the medial plane is associated with the asymmetrical functioning of medial- and lateral-pterygoid muscles, suprahyoid muscles and transitional and back temporal muscle fibres. The mean change in the length fibres of the masticator muscle and a lateral-pterygoid muscle are shown in Fig. 5A and B, respectively.

The majority of the muscles during mastication of the bread were extended from 11.8-24.1 mm, with the exception of the lateral pterygoid muscle fibres and suprahyoid muscle, the shortening of which remained at 5.5-9.4 $\mathrm{mm}$. Conversely, during the adduction movement the fibres of the lateral pterygoid and the suprahyoid muscles were elongated by $0.7-1.9 \mathrm{~mm}$. Shortening of the other muscles was $<2 \mathrm{~mm}$. The nature of the changes in muscle fibre length did not significantly depend on the consistency of the masticated food. However, during mastication of hard food, the muscles were marginally less elongated and shortened, as compared with the food with a soft consistency. The activity of the mastication muscles need to be considered with respect to the maximum range of changes in length in association with resting lengths. The activity ratio defined in this way demonstrated that the greatest activity in the working mandible was carried out by the front fibres of the medial-pterygoids and front and temporary (middle) fibres of the temporal muscles. Conversely, the lowest activity was typically observed in fibres of the lateral-pterygoid muscles, back superficial fibres of masticators and suprahyoid muscles. The results were similar during both the mastication of the bread and the hazelnuts. One of the analyses conducted was the numerical assessment of the asymmetric operation of muscle fibres during mastication. Computer simulation (Table II) demonstrated that the symmetric activity of the front temporal muscle fibres was $w_{\mathrm{P}}>0.9$. The greatest asymmetry of activity was observed in the group of lateral-pterygoids $\left(w_{\mathrm{P}}<0.44\right)$. Furthermore, the model test results suggested that the hardness of consumed food manifests itself in increased asymmetrical muscle activity, specifically visible in the superficial and deep fibres of masticators. 

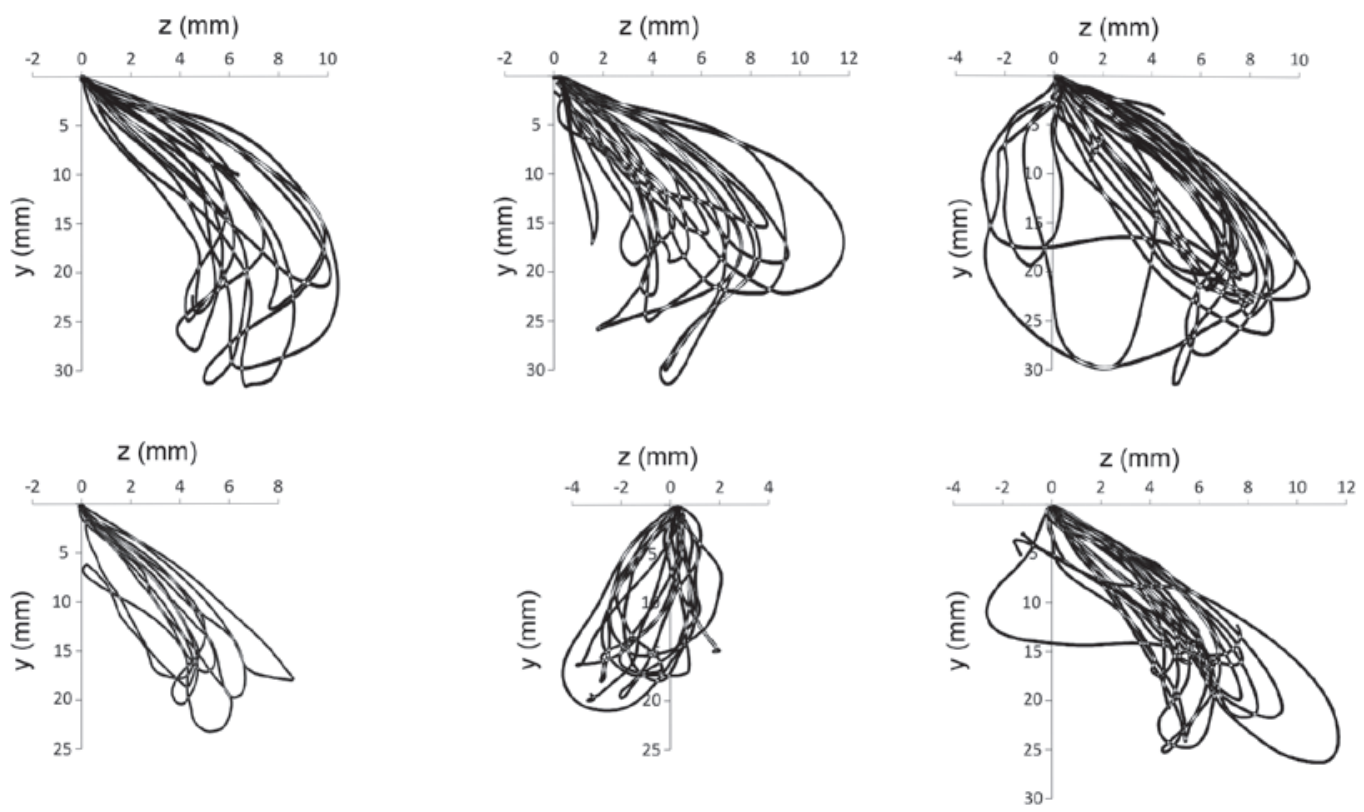

Figure 2. Registered trajectories of the incisors in the front plane during mastication of the bread, with the exception of the first cycle.
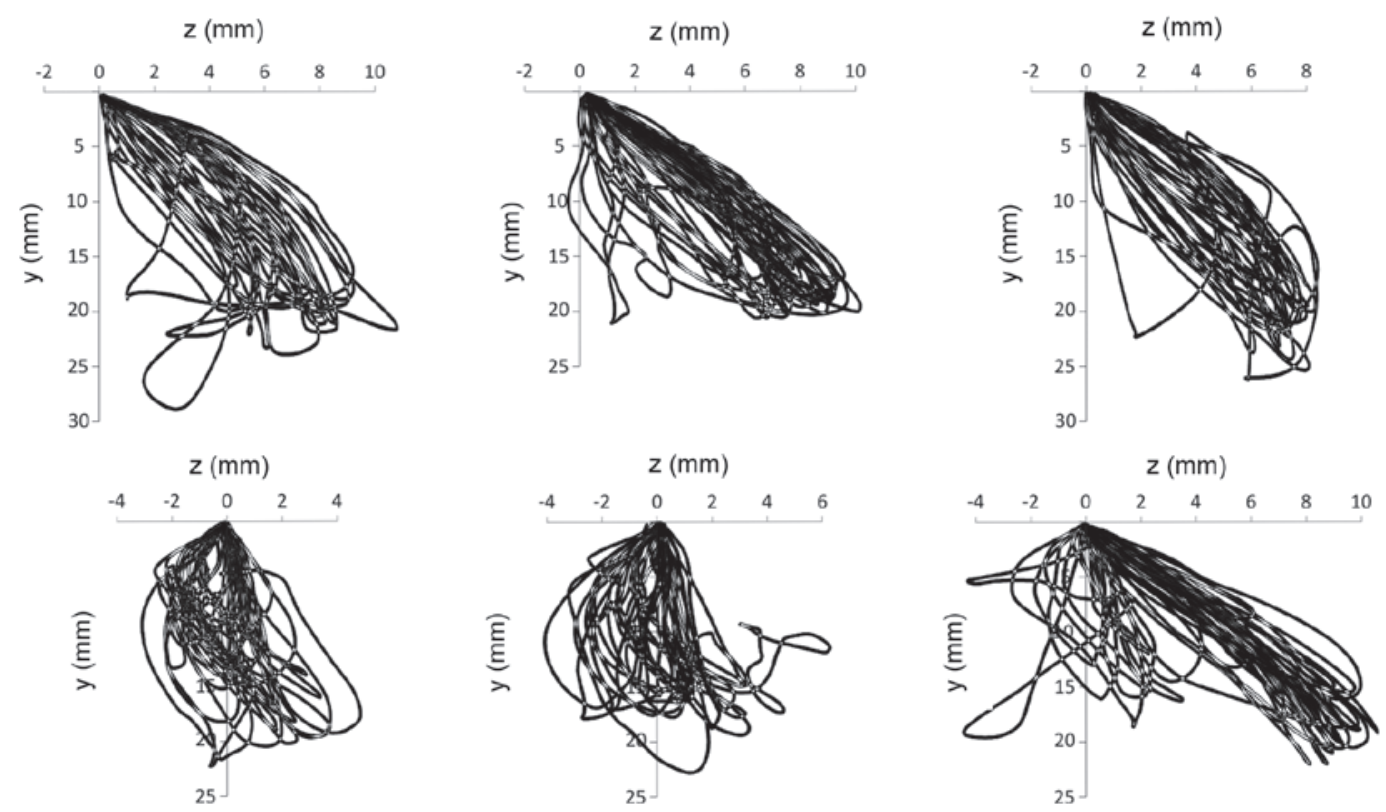

Figure 3. Registered trajectories of the incisors in the front plane during mastication of the hazelnut, with the exception of the first cycle.

\section{Discussion}

In clinical tests, the stomatognathic system should be considered as a unit, individually assigned to a patient and characteristic of that patient. The notion of the stomatognathic system, or the mastication organ, implies a system in which particular elements combine into a functional whole, both physiologically and pathologically. To examine the events taking place in the system, consideration of their mutual associations is important. A comprehensive approach of psychogenic phenomena, physiological and pathological causes of the stomatognathic system, are treated as a chain of cause and effect. $(40,41)$. These associations result from the fact that slight loss of function may cause disorders, and as a consequence may create morpho- logical changes throughout the masticatory system. One of the symptoms of masticatory organ dysfunction is acoustic signals recorded within the temporomandibular joints (42-44). Their source is the incorrect cooperation of transport disks with the heads of condyloid processes and the acetabula (19). Loss of proper functioning of the stomatognathic system is a severe limitation that manifests itself in difficulties in biting and grinding food or sound articulation $(45,46)$. However, the complexity of the muscular-skeletal system as well as its compensating capabilities enables the restoration or reduction of lost movement functions (47).

Previous studies have assessed and measured the movements of condyloid process heads and mandibular incisors (48-50). Other studies investigated the forces generated by particular 
A

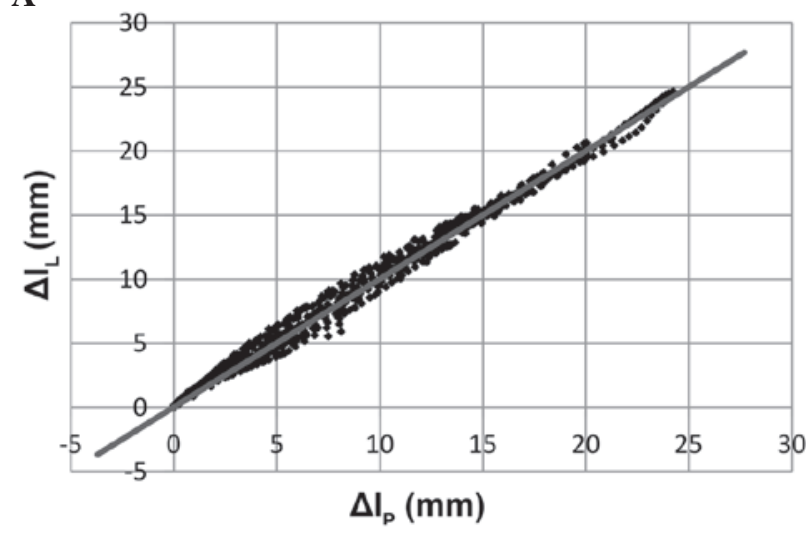

B

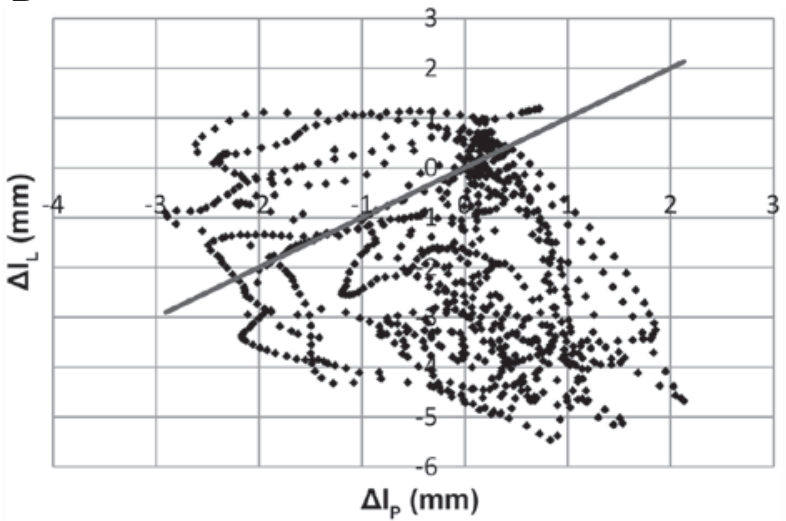

Figure 4. Sample charts illustrating the (A) symmetric and (B) asymmetric action of the muscles.

A

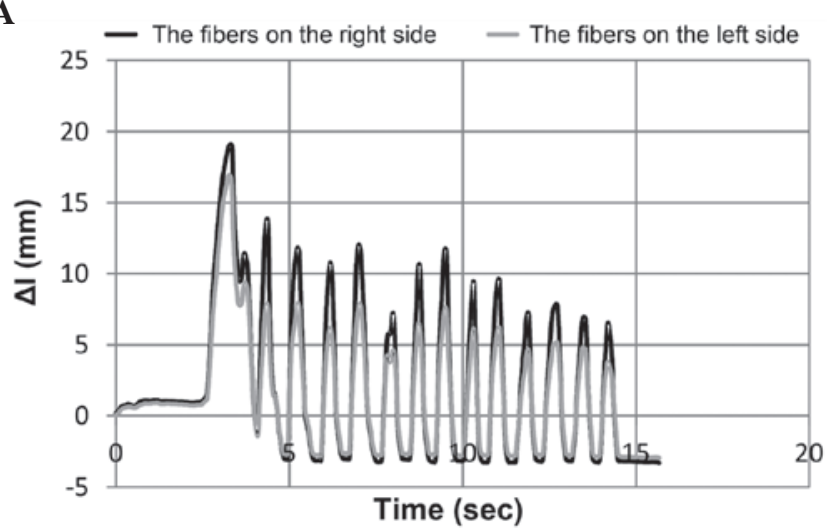

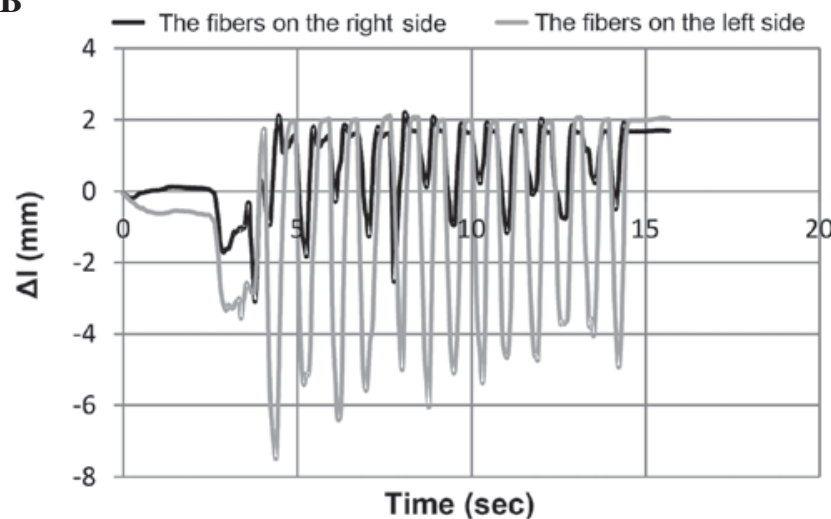

Figure 5. The mean change in the length fibres of (A) the masticator muscle and (B) a lateral-pterygoid muscle.

groups of muscle fibres $(51-56,34)$. It should be noted that direct measurement of muscle forces is difficult to achieve. To date, no technology has been developed that would permit the direct recording of muscular forces. Measurements of potential function can be carried out but only to a limited extent. These limitations result primarily from the need to breach the continuity of the skin. For this reason, novel methods are sought that will provide information regarding the activity of the mastication muscles (35-39,57-60). The results of clinical tests supplemented with model experiments may provide the basis for formulating the criteria that would enable the evaluation of forces generated by particular groups of mastication muscles. Data obtained from clinical tests does not provide clear results on the biomechanical states of the mastication muscle. In addition, kinematic models of the mastication muscle are limited to the projection of the movement of the mandible itself, ignoring the impact of changes in muscle fibres length (61-66). For this reason, the present study examined a spatial model of kinematics. Verification criteria were formulated as conformity of trajectories calculated numerically with those registered in the clinical setting. The results obtained in this way demonstrated the efficacy and suitability of the numeric model of the mastication muscle presented in the present investigation.

The model test results indicated that the maximum range of the dental arch opening during mastication of the bread was $\sim 25.3 \mathrm{~mm}$, and this value was $21.9 \mathrm{~mm}$ for the hazelnut. These scopes are close to those obtained by Hannam et al (67). The recorded trajectories of the incisors were subject to deviation from the medial plane by a $\leq 9.2 \mathrm{~mm}$ during the consumption of bread, and this deviation was slightly higher at $\sim 9.6 \mathrm{~mm}$ in the case of the hazelnut, the direction of the deviations were turned towards the load influencing the dental arches. The results of the tests did not show any significant impact of food consistency on the deviation of trajectories from the medial plane like, results which were concordant with those of Lundeen and Gibbs (3). It is also worth taking into consideration that in particular mastication cycles, the trajectories of the incisors were not always subject to deviation by the aforementioned values. This variable scope of trajectory deviations from the medial plane may be assigned to the individual habits of the subject (68), as well as the degree of food grinding. The frontal movement of the condyloid process head, situated on the balancing side was somewhat higher compared with the condyloid process head located on the working part $(\sim 6.5 \mathrm{~mm}$ for bread). Conversely, during the course of hazelnut mastication, this difference was determined to be $\sim 5.5 \mathrm{~mm}$. Vertically, the maximum displacement of condyloid process heads, by principle, assumes similar values. Insignificant differences of $\sim 0.5 \mathrm{~mm}$ for soft food (bread) and $\sim 2 \mathrm{~mm}$ for hard nuts to be associated with the positioning of dental arches of the mandible 
when biting the food. The aforementioned numeric values of the shifts of the incisors and condyloid process heads characterize the abduction phase of the dental arches. When grinding a portion of food, dental arches come into contact with each other. Regardless of the food consistency, the recorded values of the shifts was $\sim 2.3 \mathrm{~mm}$. In addition, this value corresponds approximately to the distance between the teeth at resting position. At the time of contact of the dental arches, condyloid process heads withdraw into the articular space by and average of $\sim 1.2 \mathrm{~mm}$. Nut grinding results in the condyloid process head, located at the working side, withdrawing by a maximum of $\sim 1.9 \mathrm{~mm}$. The vertical movement of the condyloid processes is limited by the anatomical structure of the temporomandibular joint and the biomechanical properties of the transport disks (69-74). Mastication is a biomechanical process that depends on numerous factors, including the shape of the dental cusps, or the preferred side of mastication in specific people (1). For this reason, it is difficult to compare the results of the present study to those obtained by previous investigators. This is because comparing results without ensuring that the same conditions were used may result in false conclusions.

The dominant componential harmonics of the amplitude-frequency spectrum were identified based on the calculated time courses and configuration coordinates. These components determine the frequency of the repetitions of the mastication cycles. Appropriate numerical calculations were used with the application of the algorithm of Fourier fast transformation. From a theoretical point of view, the majority of the information regarding the harmonic components is contained within the signal of the configuration coordinate $\Phi_{3}$, since its scope of variability is the greatest. The results of the present study determined that the average value of the dominant frequency of bread mastication was $\sim 1.16 \pm 0.06 \mathrm{~Hz}$. In the case of the hazelnut, this value was nearly twice as large at $\sim 1.84 \pm 0.07 \mathrm{~Hz}$. The identified frequencies of bread and hazelnut mastication demonstrated the impact of food consistency on the course of mastication, results which were concordant with those of Horio and Kawamura (29).

Both the results of the present study and those of Throckmorton et al (75) led to the hypothesis that the asymmetrical action of the stomatognathic system muscles results in an uneven load to the temporomandibular joint. Unbalanced muscular action may cause byorthognathic defects; these defects were reported by previous studies that used electromyography prior to and following orthognathic surgery $(76,77)$. The present study presents a mathematical approach to the model assessment of the activity of the human mastication muscle. The analytical associations characterizing the variability of the configuration coordinates were presented in a general equation. This enabled the numeric evaluation of the activity of the stomatognathic muscle system, not only with respect to the mastication cycle, but also with that of the free articulatory movements. The method presented in the current investigation may serve as a useful tool in the diagnosis of human mastication disorders.

In summary, the model and clinical tests of the present study led to the following general conclusion: Configuration coordinates calculated as a result of the solution to a reverse task of kinematics are the basis for conducting model tests, in the scope of assessment of the activity of the mastication muscles. In addition, kinematics of muscle activity can be analyzed with respect to the Cartesian coordinates, defining the location of the muscle attachments of the mandibular and cranial bones.

The spatial model of mandibular kinematics included in the present study contributes qualitatively novel information, and furthered our knowledge of the functioning of the mastication muscle. The results obtained from the computer simulations indicated that the numerical modelling of the mastication muscle is an effective tool, and may help dentists to formulate a diagnosis. Information on the spatial orientation of the muscle fibres is required in order to determine the directions of the forces generated by the muscles. Having estimated the muscle forces, future studies will strive to identify the loads affecting the structure of the temporomandibular joint.

\section{References}

1. Okeson JP: Neuroanatomy and physiology of the masticatory locomotor system from the functional side. In: Management of temporomandibular disorders and occlusion. Vol 1, 5th edition, Mosby Elsevier, St. Louis, MO, pp40-48, 2005.

2. Ahlgren J. Mechanism of mastication. Acta Odontol Scand 24 (Suppl 44): 1-109, 1966.

3. Wickwire NA, Gibbs CH, Jacobson AP and Lundeen HC: Chewing patterns in normal children. Angle Orthod 51: 48-60, 1981.

4. Gibbs CH, Messerman T, Reswick JB and Derda HJ: Functional movements of the mandible. J Prosthet Dent 26: 604-620, 1971.

5. Gibbs $\mathrm{CH}$, Lundeen HC: Jaw movement and forces during chewing and swallowing and their clinical significance. in: CH Gibbs, HC Lundeen (Eds.) Advances in occlusion. John Wright-PSG, Inc, Littleton, Mass, volume 1, 2-32, 1982.

6. Miyaoka Y, Ashida I, Iwamori H, Kawakami S, Tamaki Y, Yamazaki T and Ito N: Synchronization of masseter activity patterns between the right and left sides during chewing in healthy young males. J Med Eng Technol 38, 1-5, 281, 2014.

7. Crane EA, Rothman ED, Childers D and Gerstner GE: Analysis of temporal variation in human masticatory cycles during gum chewing. Arch Oral Biol 58: 1464-1474, 2013.

8. Slavicek G, Soykher M, Soykher M, Gruber H and Siegl P: Relevance of a standard food model in combination with electronic jaw movement recording on human mastication pattern analysis. Advances in Bioscience and Biotechnology 1: 68-78, 2010.

9. Ogawa T, Ogawa M and Koyano K: Different responses of masticatory movements after alteration of occlusal guidance related to individual movement pattern. J Oral Rehabil 28: 830-841, 2001.

10. Mongini F, Tempia-Valenta G: A graphic and statistical analysis of the chewing movements in function and dysfunction. J Craniomandib Pract 2: 125-134, 1984.

11. Hashii K, Tomida M and Yamashita S: Influence of changing the chewing region on mandibular movement, Aust Dent J 54, 38-44, 2009.

12. Henrikson T, Ekberg EC and Nilner M: Masticatory efficiency and ability in relation to occlusion and mandibular dysfunction in girls. Int J Prosthodont 11: 125-132, 1998.

13. Youssef RE, Throckmorton GS, Ellis E 3rd and Sinn DP: Comparison of habitual masticatory cycles and muscle activity before and after orthognathic surgery. J Oral Maxillofac Surg 55: 699-707, 1997.

14. English JD, Buschang PH and Throckmorton GS: Does malocclusion affect masticatory performance? Angle Orthod 72: 21-27, 2002.

15. Slavicek G: Human mastication. International journal of stomatology \& occlusion medicine 3: 29-41, 2010.

16. Kim BI, Jeong SH, Cho KH, Chung YK, Kwon HK and Choi CH: Subjective food intake ability in relation to maximal bite force among Korean adults. J Oral Rehabil 36: 168-175, 2009.

17. Proeschel P: An extensive classification of chewing patterns in the frontal plane. Cranio 5: 55-63, 1987.

18. Pröschel P, Hofmann M: Frontal chewing patterns of the incisor point and their dependence on resistance of food and type of occlusion. J Prosthet Dent 59: 617-624, 1988. 
19. Miyauchi S, Nakaminami T, Nishio K, Maruyama T: Chewing pattern in posterior crossbite. Classification of chewing pattern in the frontal plane. Nippon Hotetsu Shika Gakkai Zasshi 33: 938-951, 1989 (In Japanese).

20. Dan $\mathrm{H}$ and Kohyama K: Interactive relationship between the mechanical properties of food and the human response during the first bite. Arch Oral Biol 52: 455-464, 2007.

21. Reed DA and Ross CF: The influence of food material properties on jaw kinematics in the primate, Cebus, Arch Oral Biol 55: 946-962, 2010

22. Anderson K, Throckmorton GS, Buschang PH and Hayasaki H: The effects of bolus hardness on masticatory kinematics. J Oral Rehabil 29: 689-696, 2002

23. Horio T and Kawamura Y: Effect of texture of food on chewing patterns in the human subject. J Oral Rehabil 16: 177-183, 1989.

24. Van Der Bilt A, Engelen L, Abbink J and Pereira LJ: Effects of adding fluids to solid foods on muscle activity and number of chewing cycles. Eur J Oral Sci 115: 198-205, 2007.

25. Shiozawa M, Taniguchi H, Hayashi, Hori, Tsujimura, Nakamura, Ito K, Inoue M: Differences in chewing behavior during mastication of foods with different textures. J Text Stud 44: 44-45, 2013.

26. Wintergerst AM, Throckmorton GS and Buschang PH: Effects of bolus size and hardness on within-subject variability of chewing cycle kinematics, Arch Oral Biol 53: 369-375, 2008.

27. Lundeen $\mathrm{HC}$ and Gibbs $\mathrm{CH}$ (eds): Jaw movements and forces during chewing and swallowing and their clinical significance. In: Advances in occlusion. vol 1, 5th edition, John Wright-PSG Inc., Bristol, pp2-32 1982.

28. Horio T and Kawamura Y: Effects of texture of food on chewing patterns in the human subject. J Oral Rehabil 16: 177-183, 1989.

29. Jankelson D, Hoffman GM and Hendron AJ: The psysiology of the stomatognathic system. The Journal of the American Dental Association 46: 375-386, 1952.

30. Anderson DJ and Picton DC: Tooth contact during chewing. J Dent Res 36: 21-26, 1957.

31. Ahlgren J: Mechanism of mastication; a quantitative cinematographic and electromyographic study of masticatory movements in children with special reference to occlusion of the teeth. Acta Odontolologica Scandinavica 44: 44-45, 1966.

32. Adams SH 2nd and Zander HA: Functional tooth contacts in lateral and centric occlusion. J Am Dent Assoc 69: 465-473, 1964.

33. Martin R, Saller K: Textbook of anthropology in systematic representation with special emphasis on anthropological methods, Fischer Publishing Company, Volume 3, Stuttgart 1957.

34. Ichim I, Kieser JA and Swain MV: Functional significance of strain distribution in the human mandible under masticatory load: Numerical predictions. Arch Oral Biol 52: 465-473, 2007.

35. Bérzin F: Surface electromyography in the diagnosis of syndromes of the cranio-cervical pain. Braz J Oral Sci 10 484-491, 2004

36. Coelho-Ferraz MJP, Bérzin F and Amorim C: Electromyography Evaluations of the masticator muscles during the maximum bite force. Revista Espanola de Cirugia Oral y Maxilofacial 6: 420-427, 2008

37. Koolstra JH: Dynamics of the human masticatory system. Crit Rev Oral Biol Med 13: 366-376, 2002.

38. Castroflorio T, Icardi K, Becchino B, Merlo E, Debernardi C, Bracco P and Farina D: Reproducibility of surface EMG variables in isometric sub-maximal contractions of jaw elevator muscles. J Electromyogr Kinesiol 16: 498-505, 2006.

39. Santana-Mora U, Cudeiro J, Mora-Bermúdez MJ, Rilo-Pousa B, Ferreira-Pinho JC, Otero-Cepeda JL and Santana-Penín U: Changes in EMG activity during clenching in chronic pain patients with unilateral temporomandibular disorders. J Electromyogr Kinesiol 19: e543-e549, 2009.

40. Liu F and Steinkeler A: Epidemiology, diagnosis and treatment of temporomandibular disorders. Dent Clin North Am 57: 465-479, 2013.

41. Karibe H, Goddard G, Aoyagi K, Kawakami T, Warita S, Shimazu K, Rudd PA and McNeill C: Comparison of subjective symptoms of temporomandibular disorders in young patients by age and gender. Cranio 30: 114-120, 2012.

42. Zimmer B: Correlations between the loss of acoustic TMJ symptoms and alterations in mandibular advancement. Eur J Orthod 15: 229-234, 1993.

43. Motoyoshi M, Matsumoto Y, Ohnuma M, Arimoto M, Takahashi K and Namura S: A study of temporomandibular joint sounds. Part 2. Acoustic characteristics of joint sounds. J Nihon Univ Sch Dent 37: 47-54, 1995.
44. Prinz JF: Autocorrelation of acoustic signal from the temporomandibular joint. J Oral Rehabil 25: 635-644, 1998.

45. Poveda Roda R, Bagan JV, Diaz Fernandez JM, Hernández Bazán S and Jiménez Soriano Y: Review of temporomandibular joint pathology. Part I. Classification, epidemiology and risk factors. Med Oral Patol Oral Cir Bucal 12: E292-E298, 2007.

46. Vanderas AP and Papagiannoulis L: Multifactorial analysis of the aetiology of craniomandibular dysfunction in children. Int J Paediatr Dent 12: 336-346, 2002.

47. Chladek W: System of modeling the selected mechanical states of human mandible. Scientific Papers of Silesian University of Technology 59: 108, 2000 (In Polish).

48. Zhang X, Ashton-Miller JA and Stohler CS: Three-dimensional unilateral method for the bilateral measurement of condylar movements. J Biomech 28: 1007-1011, 1995.

49. Zuccari AG, Andres CJ and Simpson GW: A color-enhanced aid for location of the transverse horizontal opening and closing axis of the mandible. J Prosthet Dent 76: 181-186, 1996.

50. Peck CC, Murray GM, Johnson $\mathrm{CW}$ and Klineberg IJ: Trajectories of condylar points during nonworking side and protrusive movements of the mandible. J Prosthet Dent 82: 322-331, 1999

51. Osborn J and Baragar F: Predicted pattern of human muscle activity during clenching derived from a computer assisted model: Symmetric vertical bite force. J Biomech 18: 599-612, 1985.

52. Korioth TW and Hannam AG: Deformation of the human mandible during simulated tooth clenching. J Dent Res 73: 56-66, 1994

53. Meyer C, Kahn JL, Lambert A, Boutemy P and Wilk A: Development of a static simulator of the mandible. J Craniomaxillofac Surg 28: 278-286, 2000.

54. Peck CC, Langenbach GE and Hannam AG: Dynamic simulation of muscle and articular properties during human wide jaw opening. Arch Oral Biol 45: 963-982, 2000.

55. Sellers WI and Crompton RH: Using sensitivity analysis to validate the predictions of a biomechanical model of bite forces. Ann Anat 186: 89-95, 2004

56. Peck CC and Hannam AG: Human jaw and muscle modeling. Arch Oral Biol 52: 300-304, 2007.

57. Liu ZJ, Yamagata K, Kasahara Y and Ito G: Electromyographic examination of jaw muscles in relation to symptoms and occlusion of patients with temporomandibular joint disorders. J Oral Rehabil 26: 33-47, 1999.

58. Al-Saleh M, Armijo-Olivo S, Flores-Mir C and Thie N: Electromyography in diagnosing temporomandibular disorders. J Am Dent Assoc 143: 351-362, 2012.

59. Manfredini D, Cocilovo F, Favero L, Ferronato G, Tonello S and Guarda-Nardini L: Surface electromyography of jaw muscles and kinesiographic recordings: Diagnostic accuracy for myofascial pain. J Oral Rehabil 38: 791-799, 2011.

60. Ferrario VF, Sforza C, Colombo A and Ciusa V: An electromyographic investigation of masticatory muscles symmetry in normo-occlusion subjects. J Oral Rehabil 27: 33-40, 2000.

61. Leader JK, Boston J, Debski R and Rudy T: Mandibular kinematics represented by a non-orthogonal floating axis joint coordinate system. J Biomech 36: 275-281, 2003.

62. Daumas B, Xu WL and Bronlund JE: Jaw mechanism modelling and simulation. Mech Mach Theory 7: 821-833, 2005.

63. Slavicek G and Schimmer C: Analysis of human mastication behavior: a new approach using planar calculations of fragmented chewing sequences. International journal of stomatology \& occlusion medicine 3: 61-67, 2010.

64. Hayashi K, Mizoguchi I, Lee SP and Reich B: Development of a novel statistical model for mandibular kinematics. Med Eng Phys 32: 423-428, 2010.

65. Slavicek G, Soykher M, Gruber H, Siegl P and Oxtoby M: A novel standard food model to analyze the individual parameters of human mastication. International journal of stomatology \& occlusion medicine 2: 163-174, 2009.

66. Xie D, Xu WL, Foster KD, Bronlund J: Object-oriented knowledge framework for modelling human mastication of foods. Expert Systems with Applications 36: 4810-4821, 2009.

67. Hannam AG, Stavness I, Lloyd JE and Fels S: A dynamic model of jaw and hyoid biomechanics during chewing. J Biomech 41: $1069-1076,2008$

68. Pond LH, Barghi N and Barnwell GM: Occlusion and chewing side preference. J Prosthet Dent 55: 498-500, 1986. 
69. Tanne K, Tanaka E and Sakuda M: The elastic modulus of the temporomandibular joint disc from adult dogs. J Dent Res 70 $1545-1548,1991$.

70. Chin LP, Aker FD and Zarrinnia K: The viscoelastic properties of the human temporomandibular joint disc. J Oral Maxillofac Surg 54: 315-318; discussion 318-319, 1996.

71. Lai WF, Bowley J and Burch JG: Evaluation of shear stress of the human temporomandibular joint disc. J Orofac Pain 12: 153-159, 1998.

72. Tanaka E, Shibaguchi T, Tanaka M and Tanne K: Viscoelastic properties of the human temporomandibular joint disc in patients with internal derangement. J Oral Maxillofac Surg 58: 997-1002, 2000.

73. Tanaka E, Tanaka M, Jattori Y, Aoyama J, Watanabe M, Sasaki A, Sugiyama M and Tanne K: Biomechanical behaviour of bovine temporomandibular articular disc with age. Arch Oral Biol 46: 997-1003, 2001.
74. Tanaka E, Tanaka M, Miyawaki Y and Tanne K: Viscoelastic properties of canine temporomandibular joint disc in compressive load-relaxation. Arch Oral Biol 44: 1021-1026, 1999.

75. Throckmorton GS, Groshan GJ and Boyd SB: Muscle activity patterns and control of temporomandibular joint loads. J Prosthet Dent 63: 685-695, 1990.

76. Di Palma E, Gasparini G, Pelo S, Tartaglia GM and Chimenti C: Activities of masticatory muscles in patients after orthognathic surgery. J Craniomaxillofac Surg 37: 417-420, 2009.

77. Di Palma E, Gasparini G, Pelo S, Tartaglia GM and Sforza C: Activities of masticatory muscles in patients before orthognathic surgery. J Craniofac Surg 21: 724-726, 2010. 